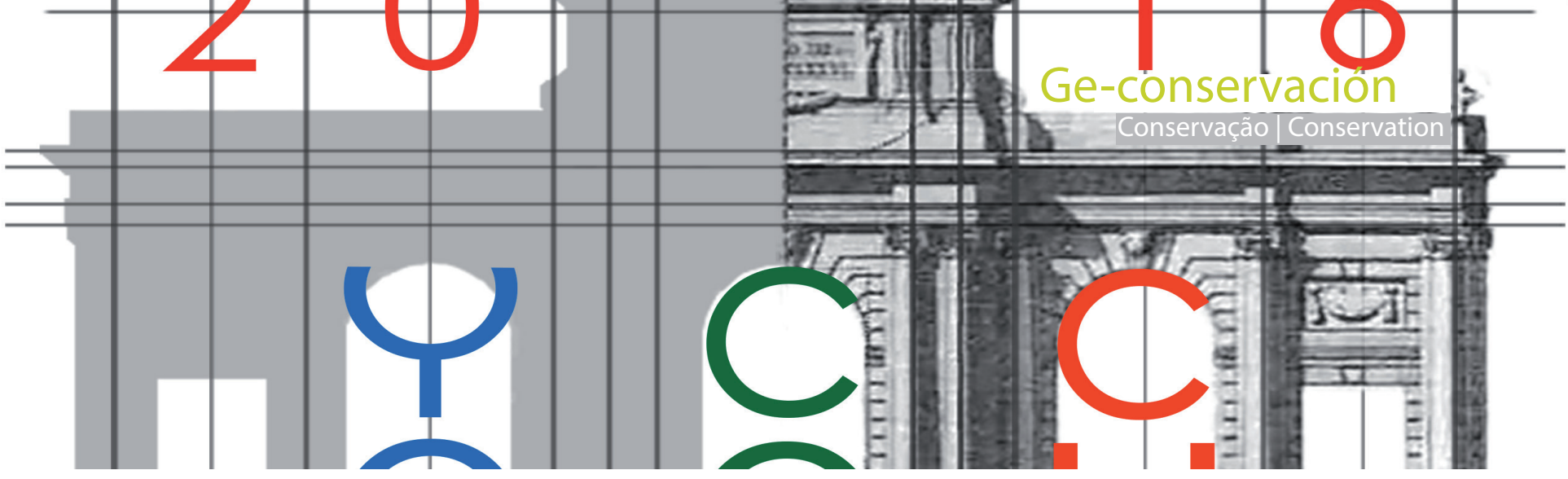

\title{
Current guidelines review for the preservation of plastics emitters of gaseous pollutants in Contemporary Art museums
}

\author{
Sara Liébana Molina
}

\begin{abstract}
Plastic contemporary artworks preservation is being a research object for the latter years. Even though so, gaseous pollutants emissions problem has not been studied in depth from the conservation-preservation field.

This article shows the results after the review on the most recent researches related to this problem. We also include the conclusions from the nineteen answers obtained from the surveys carried out in museums and institutions whose collections hold plastic made objects and pieces of art.
\end{abstract}

\begin{abstract}
The data collection analysis brings to light the absence of specific protocols for plastic preservation, even more so if it is about those emitting gaseous pollutants.
\end{abstract}

Key words: plastic, modern materials, malignant plastics, gaseous pollutants, preservation protocols, contemporary art.

\section{Revisión de protocolos actuales para la conservación de plásticos emisores de contaminantes gaseosos en los museos de Arte Contemporáneo}

Resumen: La conservación de obras de arte contemporáneo realizadas en plástico viene siendo objeto de investigaciones en los últimos años. Sin embargo, el problema de las emisiones de contaminantes gaseosos no ha sido estudiado en profundidad desde el campo de la conservación-restauración.

En este artículo presentamos los resultados obtenidos tras la revisión de las últimas investigaciones relacionadas con éste problema. También incorporamos las conclusiones extraídas de las diecinueve respuestas obtenidas de las encuestas realizadas a museos e instituciones, en cuyas colecciones albergan obras de arte y objetos realizados en plástico.

El análisis de la información recogida, pone de manifiesto la carencia de protocolos específicos para la conservación de plásticos, más aún si se tratan de los emisores de contaminantes gaseosos.

Palabras clave: plástico, materiales contemporáneos, plásticos contaminantes, contaminantes gaseosos , protocolos de conservación, arte contemporáneo.

\section{Introduction}

Plastics; we understand as such the combined natural polymers, semi-synthetic or synthetic, and their additives; were incorporated into the world of art at the beginning of the 20th Century. They keep growing in the design, and contemporary art collections. Thus, they signify a high percentage in the most relevant collections.

On the first decades plastics showed some instability, which forewarned a pressing need of research. Thus, from the first moment $(90$ 's), there were studies, related with conservation of contemporary art (Grattan 1993; Heuman 1995; Corzo 1999; Hummelen \& Sillé 1999), within which plastic conservation was addressed. The specific ones for this material appeared by the end of the 20th Century (Blank 1990; Fenn 1995; Quye \& Williamson 1999; Williams 2002; Oosten et al. 2002; Albus et al. 2007; Keneghan et al. 2008; Shashoua 2008b; Waentig 2008; Oosten 2011; Smithsonian Science 2012; Cadiñanos 2012; Lavédrine et al. 2012).

Time means a threat for these materials, and it has turned their conservation into a challenge; this domain is where this research takes place. 
Plastics undergo irreversible deterioration processes with no treatment nowadays to guarantee their stability. As a consequence, preventative conservation is the only strategy to protect them. Therefore, it is required to have a specific conservation protocol to keep them in the best feasible condition.

Malignant plastics are those that when deteriorating, produce harmful emissions that may damage additional objects whether plastics or not (Williams 2002), and thus they become a new degenerating source.

Research in this area has begun but it is in an emerging state, since there are mainly specific study cases being addressed. It is difficult to find general examples that identify and describe plastics or analysis of the preservation condition of this material.

This article collects the following targets: review current research studies about the problematic on plastic made art pieces producing gaseous pollutants emissions; getting to know the protocols used for this material conservation in the contemporary art collections; show surveys efficiency as a tool for gathering unpublished information; critically analyse data obtained in order to know the deficiencies that may arise aiming to elaborate a protocol suggestion. Always within the scope of contemporary art preservation.

\section{Methods \& methodology}

The research is structured in two parts: the study of the bibliographic sources and the inquiries.

The review has been done on the studies that refer design or contemporary art works with COVs emissions, since it has been noticed a lower number of those studies.

Surveys have two parts; a first one with the aim of knowing the existence of a specific protocol for plastics preservation. If there is one, a copy will be requested.

The second part (without protocol) consists of five questions directed to know each one of the values and standards used as preservation measures, and if they follow any external guideline.

The aforementioned enquires have been sent to fifty museums, both European and American, selected founded on: the importance of their collections, the larger presence of plastic-made works, or for being involved in projects related to this material preservation.

The last part of the methodology, consist in making the qualitative and quantitative analysis, where the conclusions have originate from.

\section{Malignant Plastics}

Polluting plastic's danger in Contemporary Art Collections is a problem that we only have elementary notions about, especially based on experience. There are seven research works (Fenn 1995; Keneghan \& Quye 1999; Williams 2002; Shashoua 2008b; Kean 2009; Tsang et al. 2009; Lavédrine et al. 2012) that refer to the pollutant emissions from the artwork, but all of them only give an superficial overview of the problem. All seven studies warn us about the risk of gaseous pollutants emissions generated by specific types of plastics during their deterioration process, which may impact nearby pieces of work, both in exhibit or storage.

All of them also point at cellulose acetate, cellulose nitrate and Poly (vinyl chloride) as dangerous; five add polyurethane to this list; and two add rubber.

It is worth mentioning at this point, that there are also some research as The Museum Environment (Thomson 1978), Airborne Pollutants in Museums, Galleries, and Archives: Risk Assessment and Control Strategies(Tétreault 2003), Monitoring for Gaseous Pollutants in Museum Environments(Grzywacz 2006), among other, that refer to the pollutant emissions from other objects (showcases, container, etc.).

Consequently, it seems clear that all the artworks made by such five plastics need a specialized treatment that has to be taken in account when making a specific convention in order to preserve this material.

\section{-What are gaseous pollutant emissions by plastic?}

When plastics are exposed to sources of extrinsic deteriorating, such as light, ultraviolet radiation, temperature, humidity, oxygen and pollutants, chemistry reactions alter their qualities. When this happens, the appearance of degraded products released by the object often occurs, they agree with the migration of compounds added for their production and may be found in solid, liquid or gaseous state.

The appearance of deposits on plastic surfaces is generally due to plasticizer migrations, or occasionally due to fillers. When they are gaseous they may have characteristic odours, due to the unpredictable compounds' release (Balcar et al. 2012) .

These emissions may unleash or accelerate the ageing in other objects.

Consequently, some plastics are potentially dangerous, since these emissions may unleash or accelerate the ageing in other objects situated nearby. 
-What do they emit?

It has also been detected which gases are sent out by these five plastic types. In this table the potentially dangerous plastics, and which are the most common gases they send out are pointed out (Lavédrine et al. 2012; Williams 2002).

Table 1.- Malignant plastics and their most usual emissions

\begin{tabular}{|l|l|}
\hline Plastic & Gas emissions \\
\hline Cellulose acetate & Acetic acid gas \\
\hline Rubber, ebonite and vulcanite & $\begin{array}{l}\text { Hydrogen sulphide and other sulphur } \\
\text { containing gases }\end{array}$ \\
\hline Cellulose nitrate & $\begin{array}{l}\text { Acidic and oxidizing nitrogen oxide } \\
\text { gases }\end{array}$ \\
\hline Polyurethane & Nitrogenous organic gases \\
\hline PVC & $\begin{array}{l}\text { May produce hydrochloric acid gas } \\
\text { under extreme conditions of moisture } \\
\text { and light exposure }\end{array}$ \\
\hline
\end{tabular}

-How are they identified?

This identification may be done by different scientific analyses or by empiric analytic method. We find Condition Reports use the second one (Liébana, in press). Also, we notice that there is an important number of research describing which are the most typical odours released by each kind of plastic.

As example, we can find two samples of Condition Report specific for plastics including a section referring odors detected in the following books: "Basic Condition Reporting. A Handbook"(Demerouskas 1998, p.121) and "Preservation of Plastic Artefacts in museum collections"(Lavédrine et al. 2012, p.295).

It is worth mentioning at this point, that the odours are very subjective, therefore they will allow us to identify a threat in our collection, but by no means will determine a specific cause. Furthermore, there are gaseous pollutants odourless, so it could be given such a risk condition without being able to empirically perceive it at an early phase.

\section{Potential casualties}

Literature has also mentioned materials, which are susceptible to suffering damage due to these emissions. Six, out of seven works dealing with the problem, list the most potentially sensitive materials. All of them agree that, emissions affect the same plastics; five of them point out they are a potential risk for metals, two of them warn of the hazard meant for paper and Shashoua (2008) mentions how detrimental they can be for organic materials in general.

So, making a recompilation of yield results until now, we may conclude that the materials susceptible to these pollutants, are metals and organic materials

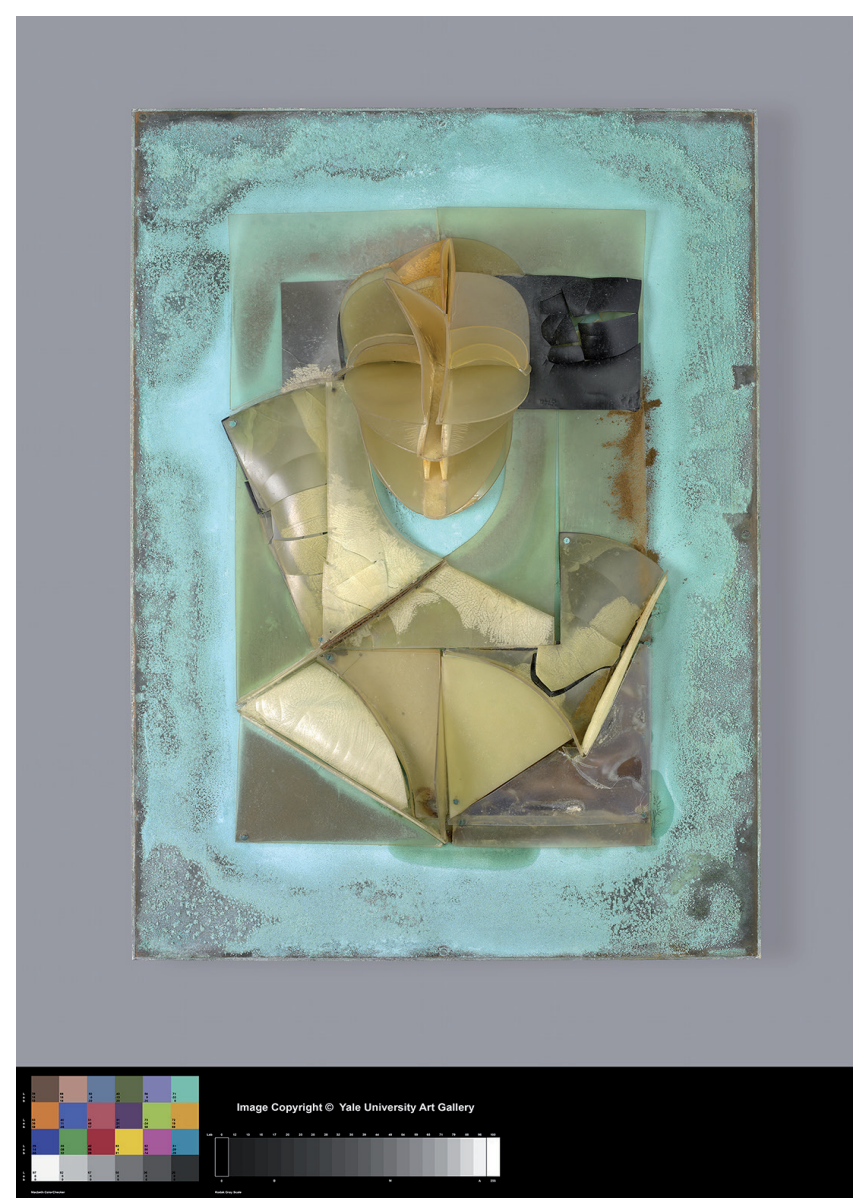

Figure 1.- Originally the work presented transparent plastic elements, now shows plastic decomposition signs, which cause deterioration processes on metallic parts. Portrait of Marcel Duchamp, Antoine Pevsner, 1926, Cellulose nitrate on copper with iron. Yale University Art Gallery Gift of Collection Société Anonyme.]

between which we may point at paper and plastics, more specifically fully vulcanised hard rubber (ebonite and vulcanite).

\section{Plastic preservation at museums and institutions}

In order to know whether there are or there are not protocols used for plastic conservation in the art conservation collections, fifty inquires have been sent to American and European collections with a result of nineteen answers, four of which did not answer to the second part.

The first part results reveal a lack of protocols supported by all nineteen of them.

The answers on the second part show heterogeneity on norms and parameters taken in account for physical plastic material preservation in each one of the collections. As opposed to decision making where a closer affinity of criteria may be observed.

Surveys section two. Standards; summary of findings. 
Table 2.- * In rubber for exceptional cases. (Chart legend):

Guideline 1: Are the same parameters used for art works in good preservation condition as for those that have some type of damage? Guideline 2: Are damage and pieces in good condition stored and exhibited together?

Guideline 3: Do you do any kind of maintenance (e.g. preventative cleaning) such as conservation measures?

Guideline 4: Is there any control of pollutant gas emissions?

Guideline 5: Personalized decision-making?

\begin{tabular}{|c|c|c|c|c|c|}
\hline Institutions & Guideline 1 & Guideline 2 & Guideline 3 & Guideline 4 & Guideline 5 \\
\hline Kunststoff-museums-verein e. v. & $\mathrm{N}$ & $\mathrm{N}$ & - & - & - \\
\hline Museum of design in plastic (modip) & $\mathrm{Y}$ & $\mathrm{N}$ & - & $\mathrm{N}$ & $\mathrm{Y}$ \\
\hline SMK & $\mathrm{Y}$ & $\mathrm{Y}$ & - & $\mathrm{N}$ & $\mathrm{Y}$ \\
\hline Tampere museum & - & $\mathrm{Y}$ & - & $\mathrm{Y}$ & - \\
\hline Victoria \& Albert museum & Y & $\mathrm{N}$ & - & $\mathrm{N}$ & - \\
\hline $\begin{array}{l}\text { Die neue sammlung -The international } \\
\text { design museum }\end{array}$ & $\mathrm{N}^{*}$ & $\mathrm{Y}$ & - & - & $\mathrm{Y}$ \\
\hline Denver art museum & $\mathrm{Y}$ & $\mathrm{Y}$ & - & $\mathrm{Y}$ & $\mathrm{Y}$ \\
\hline Moma & - & $\mathrm{N}$ & - & - & $\mathrm{S}$ \\
\hline Pinacoteca do estado de São Paulo & $\mathrm{Y}$ & $\mathrm{Y}$ & - & $\mathrm{N}$ & $\mathrm{Y}$ \\
\hline Centro andaluz de arte contemporáneo & $\mathrm{Y}$ & $\mathrm{Y}$ & - & $\mathrm{N}$ & $\mathrm{Y}$ \\
\hline Centro atlántico de arte moderno & Y & $\mathrm{Y}$ & $\mathrm{Y}$ & $\mathrm{N}$ & $\mathrm{Y}$ \\
\hline Guggenheim Bilbao & $\mathrm{Y}$ & - & - & Y & $\mathrm{Y}$ \\
\hline Museo Vostell malpartida & $\mathrm{Y}$ & $\mathrm{N}$ & $\mathrm{Y}$ & $\mathrm{N}$ & Y \\
\hline Museo artium & $\mathrm{Y}$ & - & $\mathrm{Y}$ & - & $\mathrm{Y}$ \\
\hline Fundación gala salvador dalí & $\mathrm{Y}$ & $\mathrm{N}$ & $\mathrm{Y}$ & $\mathrm{N}$ & $\mathrm{Y}$ \\
\hline
\end{tabular}


In summary:

- Eleven museums set the environmental parameters according to the preservation condition of the piece of art, two don't, and two have not commented.

- Seven store or exhibit at the same time works in good conservation condition, and deteriorated ones, six don't do it, and two have decline any answer. It must be noted that, the vast majority who do not follow this norm, attribute it to space or curator problems.

- Four make some type of maintenance as a preservation measure, while all others have not answered that question. Only three museums make some type of gaseous pollutants emissions control, eight have confirmed they do not make any, and four have not answered. It must be noted that the three making some controls are all different; Tampere Museum uses an equipment that allows a gaseous pollutants general control in real time; Denver Art Museum make a periodical empiric control (smell) and the Guggenheim Bilbao uses AD-strips, thus it is only making a follow up of volatile organic acids.

- Finally all the Museums, that have answered, make their decisions individualized. We ignore the routine for the three that have not answered.

\section{Information analysis: protocol-devising proposal}

It is found out that there is no preservation protocol for plastic materials, which are considered indispensable. Shashoua confirms this fact in her recent article "A safe place. Store strategies for plastics" telling that "Since there are no international standards for storage environments for plastics, it is not uncommon for museums to apply those used to preserve both works of art on paper and other fragile organic materials".

Given the material characteristics and the detriment noticed along its lifetime, it is advisable to pay special attention to it, since the chemical deterioration may even cause its disappearance. On the other hand, it implies a potential risk for other works kept under the same place. Therefore, it is considered of paramount importance to elaborate an action protocol based on two crucial mainstays: material preservation and action guidelines. This protocol should enable us to regulate the steps to follow in a first decision-making.

\section{-Material preservation}

Plastic deterioration happens in two stages along its life: on its manufacture and on its "use". In this second phase it is constantly exposed to environmental factors. Prolonged exposures to light, heat, humidity, oxygen and pollutant gasses may visibly reduce its longevity (Shashoua 2008b).

Thereby, it must be estimated which are the best environmental values, both in storage and in exhibit, in order to develop a protocol. To achieve this target all deteriorating factors above mentioned have to be monitored.

So, materials preservation should consider the illumination parameters both in storage and in exhibit. Considering any type of light is detrimental for plastic stability, particularly if containing UV radiation; and the fact that hazard impacts are accumulative and therefore irreversible.

Accordingly, excluding light on storage areas and limiting it during exhibitions is recommended. As a consequence, it is recommended to restrict light in halls only when open to the public, considering that illumination must be artificial, free from UV radiations and limited to 50 lux.

Temperature is a key influence in deterioration processes, although it is proven that plastic tolerance range is quite wide.

One occurrence to bear in mind when talking about temperature is the day/night fluctuations, since not all collections are in a conditioned environment. It is proven to have a direct impact on its physical stability due to the relatively high thermal expansion coefficient this material has.

Temperaturealsohasamajorimpactonchemicaldegradation processes, according to Michalski (2002)"Double the life for each five-degree drop, [...]", to this effect cold storage is considered a positive preservation measure. Nevertheless this system could lead to material damage as crackles or splits resulting from the cold-warm alternate processes. On account of this, an individual use must be determined, case by case, in order to assess its effectiveness. We also deem necessary further research aiming to reveal which measures have to be implemented to minimize the risk that adopting this system means nowadays.

Humidity is linked directly with all factors provoking HR fluctuations such as public attendance; so in exhibit periods it is recommended to keep it controlled by $40-50 \%$ and this way avoid certain plastics hydrolysing (Blank 1990; Keneghan \& Quye 1999).

For cold storage this matter should be equally considered, since a maximum span of $6^{\circ} \mathrm{C}-10^{\circ} \mathrm{C}$ between plastic and container should not be surpassed to avoid condensation derived from the cooling process. Carrlee (2003) holds that keeping those parameters is crucial to avoid this process and suggests surrounding the work with an isolation material like polystyrene foam chips to achieve this.

Polymers are oxidized in all their life cycle phases - during manufacturing and processing, as well as during storage and use. Oxidation nevertheless, does not happen at the 
same speed during all the polymer life stages (Shashoua 2008b).

This type of deterioration reduces plastic physical properties and changes its appearance. Most common symptoms are a decrease in malleability, strength and flexibility, as well as, discolouration, surface cracks and increase in porosity (lbid.).

Aiming to slow down these modifications, systems like anoxia storages both in nitrogen atmosphere and in water, or placing oxygen absorbers in the packaging systems designed for this purpose, have been evaluated.

These methods nevertheless, require further investigation, since there are some knowledge gaps about some of them, which initially seem able to produce very interesting results.

Concerning oxygen absorbers, Ageless ${ }^{\circledR}$ is the right method for rubber preservation, since there are examples of its effectiveness, whereas it can be hazardous for all other plastics analysed here; AC, NC, PU, PVC since it produces a increase in HR in the packaging (Shashoua 1999).

RP-K${ }^{\circledR}$ "absorber", yet lacking a deep study about its efficiency on "malignant plastics", is considered as an interesting option based on its efficiency for absorbing not only oxygen but other molecules, and unlike Ageless ${ }^{\circledR}$ keeps HR stable.

As for nitrogen atmosphere, although it may yield good results, its handling is more problematic since it may be hazardous for human beings, which complicates periodical artwork control. Accordingly, it is initially dismissed, although it could be considered in very specific cases.

We consider that underwater storage needs detailed examination enabling analysis of its pros and cons, Since no trials have been performed to proof the effectiveness of this approach, and although in principle exposes various risk, in rare instances rubber objects have been found submerged under water in surprisingly good condition (Grieve 2008).

As it is being considered along the full article, pollutants are a riskfactor when preserving a plastic made artwork collection. Therefore, excluding them from their environment would be necessary for their right preservation.

It is recommended storing pieces of art in places as open as possible. If packaging is required, the materials used should be acid free, and adhesive labels should not be used at all.

As in the case of oxygen, we may also use absorbers to minimize the risk. These can be installed in the active filter system, in the storing area or inside the packaging material (Shashoua 2008a).

From existing scavengers, both activated carbon, as zeolites seem to report good results for certain plastics preservation. Although, this review also proves the need of studies in more depth that will enable to make the most out of those products.

\section{Action criteria}

The action guidelines in plastic preservation protocols must be focused on slowing deterioration, since up till now this cannot be stopped. There will be various deteriorating stages during its lifetime, being the reason why the steps to take will have to be necessarily different for each one.

As they are pieces of art, material preservation, must care also about conceptual conservation, for in case of extreme degradation, some questions should be answered as what measures to take, or if a replica would be acceptable between others.

The literature review on projects analysing most common plastics deteriorating sources and feasible solutions to inhibit them, shows that most of them focus on specific aspects, doing isolated researches, without taking in account plastic preservation general problems. From the review of fifteen studies only one of them (Shashoua 2008b) takes in account all aspects. Three of them (Blank 1990; Albus et al. 2007; Waentig 2008) although leaving out some, make also a global study quite complete. All others are centred in specific aspects.

Since the curator-contemporary art conservator aim is preserving the artist intention, stopping physical change, before taking action, we have to rely on a well-structured work methodology that may allow removing subjectivity from decision-making.

\section{Conclusions}

The literature review confirms that only seven research studies deal in a general way with the issue of gaseous pollutants, except Williams (2002) who does it in a specific way.

In the same way, they point at five plastics as dangerous because of their gaseous pollutants emissions: AC, NC, PVC, polyurethane and rubber. NOx, and acid, and sulfurous gases, are the most commonly expelled.

Condition Reports show that the empirical method is used only to detect gaseous pollutants, even though there are more reliable scientific methods, that not only detects gaseous pollutants emissions sooner, but also allows data records.

Surveys show some information that is not possible to obtain through bibliographic review, as it is the inexistence of specific protocols for plastic preservation.

They also confirm that scientific gas control is not generalized, aside from the exceptions aforementioned. This deficiency is related to budget matters, although some of the devices do not imply a high cost. 
Finally, this research shows the lack of space and budget as decisive factors on decision making that negatively impact plastic preservation in collections. Nevertheless, a greater cooperation between museums curators, and researchers would significantly better the issue, since it would allow a deeper study for specific cases.

\section{Bibliography}

ALBUS, S. ET AL. (2007). Plastic Art: A Precarious Success Story, AXA Art Insurance Corporation.

BALCAR, N., LATTUATI-DERIEUX, A. \& VILA, A. (2012). Appendix 3: Analysis of degradation products found during surveys of three French collections. In B. Lavédrine, A. Fournier, \& G. Martin, eds. Preservation of Plastic Artefacts in museum collections. pp. 302-308.

BLANK, S. (1990). An introduction to plastics and rubbers in collections. Studies in Conservation, 35(2), pp.53-63. Available at: http://www.maneyonline.com/doi/abs/10.1179/sic.1990.35.2.53 [Accessed December 4, 2014].

CADIÑANOS, S. (2012). PRIMI projects (Plastic Research and Innovation for Museum and Industry). In Conservación de Arte Contemporáneo 13a Jornada. Madrid: MNCARS, pp. 245-252.

CARRLEE, E. (2003). Does Low-Temperature Pest Management Cause Damage? Literature Review and Observational Study of Ethnographic Artifacts. Journal of the American Institute for Conservation, 42(2), pp.141-166. Available at: http://www.jstor. org/stable/3180068? origin=crossref.

CORZO, M.A. ed. (1999). Mortality Immortality?: The Legacy of 20th-century Art, Los Ángeles: Getty Publications.

DEMEROUSKAS, M. ed. (1998). Basic Condition Reporting. A Handbook, Manhattan: Southeastern Registrars Association.

FENN, J. (1995). Secret sabotaje: reassessing museum plastics in display and storage. In M. Wright \& J. Townsend, eds. Pre-prints of SSCR's 2nd conference held at the Department of Zoology, University of Aberdeen, 13-14 September 1995. Edinburgh: The Scottish Society for Conservation \& Restoration, pp. 38-41.

GRATTAN, D.W. ed. (1993). Saving the 20th Century, the Conservation of Modern Materials: Proceedings of a Conference Symposium '91, Saving the Twentieth Century, Ottawa, Canada, 15 to 20 September, 1991, Ottawa: Canadian Conservation Institute.

GRIEVE, S. (2008). The excavation, conservation, storage, and display of rubber artifacts recovered from USS monitor (1862). The journal of American Institute for Conservation, pp.139-148. Available at: http://www.maneyonline.com/doi/ pdfplus/10.1179/019713608806112151.

GRZYWACZ, C.M. (2006). Monitoring for Gaseous Pollutants in Museum Environments, Los Ángeles: The Getty Conservation Institute.
HEUMAN, J. ed. (1995). From marble to chocolate: the conservation of modern sculpture: Tate Gallery Conference, 18-20 September 1995, London: Archetype.

HUMMELEN, IJ. \& SILLÉ, D. eds. (1999). Modern Art - who Cares?: An Interdisciplinary Research Project and an International Symposium on the Conservation of Modern and Contemporary Art, Amsterdam: Archetype.

KEAN, S. (2009). Does Plastic Art Last Forever?. Not even close. Can a generation of synthetic objects be saved? Available at: <http://www.slate.com/articles/arts/art/2009/07/does_plastic_ art_last_forever.single.ht $\mathrm{ml}>$ [Accessed May 6, 2014].

KENEGHAN, B., BETTS, L. \& EGAN, L. eds. (2008). Plastics: Looking at the Future and Learning from the Past: Papers from the Conference Held at the Victoria and Albert Museum, London, 23-25 May 2007, London: Archetype.

KENEGHAN, B.\&QUYE, A. (1999). Degradation-Part 2:Degradation Causes. In A. Quye \& C. Williamson, eds. Plastics-Collecting and Conserving. Edinburgh: National Museum of Scotland, p. 127.

LAVÉDRINE, B., FOURNIER, A. \& MARTIN, G. eds. (2012). Preservation of Plastic Artefacts in Museum Collections, Francia: CTHS.

LIÉBANA MOLINA, S. (In Press). Plastics emitters of gaseous pollutants in Contemporary Art collections: protocols review for its conservation. In: 5th International Conference Youth in Conservation of Cultural Heritage YOCOCU 2016 Congress Book. Madrid: MNCARS.

MICHALSKI, S. (2002). Double the life for each five-degree drop, more than double the life for each halving of relative humidity. In R. Vontobel, ed. 13th ICOM-CC Triennial Meeting Rio de Janeiro, 22-27 September 2002. James\&James Ltd., pp. 66-72.

OOSTEN, T. VAN. (2011). PUR Facts: conservation of polyurethane foam in Art and Design, Amsterdam: Amsterdam University Press.

OOSTEN, T. VAN, SHASHOUA, Y. \& WAENTIG, F. eds., 2002. Plastics in Art: History, Technology, Preservation, Munich: Siegl.

QUYE, A. \& WILLIAMSON, C. eds. (1999). Plastics - collecting and conserving, Edinburgh: National Museum of Scotland.

SHASHOUA, Y. (2008a). Conservation of plastics: is it possible today? In Plastics. Looking at the future and learning from the past. Londres: Archetype publications Ltd.

SHASHOUA, Y. (2008b). Conservation of plastics. Materials, science, degradation and preservation, Oxford: $\mathrm{BH}$.

SHASHOUA, Y. (1999). Part 4: Conservation research in the 1990s. In Plastics - Collecting and Conserving. Edinburgo: NMS Publishing Ltd.

SMITHSONIAN SCIENCE (2012). The Age of Plastic: symposium June 7 \&8 2012. Available at: http://smithsonianscience.org/2012/06/theage-of-plastic-symposium- june-7-8-2012/ [Accessed April 18, 2014]. 
TÉTREAULT, J. (2003). Airborne Pollutants in Museums, Galleries, and Archives: Risk Assessment and Control Strategies, Ottawa: Canadian Conservation Institute.

THOMSON, G. (1978). The Museum Environment, London: Butterworht-Heinemann.

TSANG, J. et al. (2009). Degradation of Lumarith'Cellulose Acetate. Examination and chemical analysis of a salesman's simple kit. Studies in Conservation. Available at: http://www.maneyonline. com/doi/abs/10.1179/sic.2009.54.2.90.

WAENTIG, F. (2008). Plastics in Art: A Study from the Conservation Point of View, Colonia: Imhof.

WILLIAMS, R.S. (2002). Care of plastics: Malignant plastics. WAAC Newsletter. Available at: http://cool.conservation-us.org/waac/ wn/wn24/wn24-1/wn24-102.html.

\section{Acknowledgements}

I am grateful to my doctoral supervisor Ma Pilar Bustinduy for her patience and good advices.

I also appreciate the financial support from the UPV/EHU.

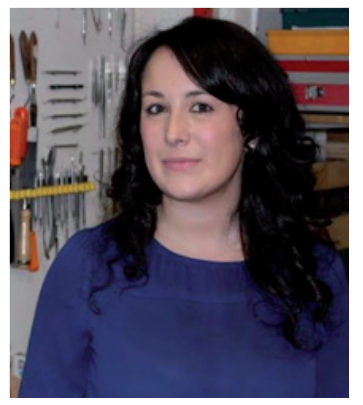

\section{Sara Liébana Molina}

sara.liebana.molina@gmail.com

Degree in Fine Arts, specialised in Conservation and Restoration of Cultural Heritage; and Master Degree in Conservation and Exhibition of Contemporary Art. I am currently a pre-doctoral fellow of the University of the Basque Country - UPV/EHU. I have also completed internships at Guggenheim Museum Bilbao and Bilbao Fine Arts Museum, among others. 